Syntax Literate: Jurnal Ilmiah Indonesia p-ISSN: 2541-0849 e-ISSN: 2548-1398

Vol. 6, Spesial Issue No. 1, November 2021

\title{
APAKAH BUDAYA ORGANISASI PEMBELAJARAN DAPAT MEMODERASI HUBUNGAN TIDAK LANGSUNG ANTARA CORE SELF-EVALUATION DAN KREATIVITAS KARYAWAN MELALUI MOTIVASI INTRINSIK
}

\section{Affan Maulana Ghiffari, Debora Eflina Purba}

Fakultas Psikologi Universitas Indonesia (UI) Depok, Jawa Barat, Indonesia

Email: affan.maulana91@ui.ac.id, eflina@ui.ac.id

\begin{abstract}
Abstrak
Dalam lingkungan pekerjaan yang sangat dinamis dan penuh ketidakpastian, organisasi atau perusahaan membutuhkan sumber daya yang dapat diandalkan untuk dapat bertahan, bersaing dan berkembang. Salah satu bentuk sumber daya yang dapat digunakan adalah kreativitas karyawan. Penelitian ini bertujuan untuk meneliti hubungan tidak langsung antara core self-evaluation (CSE) dengan kreativitas karyawan melalui peran mediasi motivasi intrinsik, serta melihat peran budaya organisasi pembelajaran dalam memoderasi hubungan antara motivasi intrinsik dengan kreativitas karyawan. Penelitian ini juga melihat hubungan tidak langsung antara CSE dengan kreativitas melalui motivasi intrinsik, yang dimoderasi oleh budaya organisasi pembelajaran pada hubungan antara motivasi intrinsik dengan kreativitas karyawan. Penelitian dilakukan terhadap 144 karyawan BUMD. Uji hipotesis menggunakan Hayes' PROCESS Macro model 14 menunjukkan bahwa motivasi intrinsik memediasi hubungan antara CSE dengan kreativitas karyawan. Namun demikian, budaya organisasi pembelajaran tidak memoderasi hubungan antara motivasi intrinsik dengan kreativitas karyawan. Hasil juga menunjukkan bahwa hubungan tidak langsung antara CSE dengan kreativitas karyawan yang dimediasi oleh motivasi intrinsik, tidak dimoderasi oleh budaya organisasi pembelajaran pada hubungan antara motivasi intrinsik dan kreativitas karyawan.
\end{abstract}

Kata Kunci: kreativitas karyawan; core self-evaluation; motivasi intrinsik; budaya organisasi pembelajaran

\section{Abstract}

In highly dynamic and uncertain work environment, organizations or companies need reliable resources to survive, compete and develop. One form of resource that can be used is employee creativity. This study aimed at investigating the relationship between core self-evaluation (CSE) and employee creativity mediated by intrinsic motivation, and to see the role of organizational learning culture in moderating the relationship between intrinsic motivation and employee creativity. This study also looked at the indirect relationship between CSE and employee creativity through intrinsic motivation, which is moderated by organizational learning culture on the relationship between intrinsic motivation and employee creativity. The study was conducted on 144 BUMD employees. Hypothesis testing 
using the moderated-mediation Hayes' PROCESS Macro model 14 shows that intrinsic motivation mediates the relationship between CSE and employee creativity. However, organizational learning culture does not moderate the relationship between intrinsic motivation and employee creativity. The results also show that the indirect relationship between CSE and employee creativity mediated by intrinsic motivation, not moderated by organizational learning culture on the relationship between intrinsic motivation and employee creativity.

Keywords: employee creativity; core self-evaluation; intrinsic motivation; learning organizational culture

\section{Pendahuluan}

Dalam lingkungan pekerjaan yang sangat dinamis dan penuh ketidakpastian seperti sekarang ini, organisasi atau perusahaan membutuhkan sumber daya yang dapat diandalkan untuk dapat bertahan, bersaing dan berkembang. Salah satu bentuk sumber daya yang dapat digunakan adalah kreativitas karyawan (Wang, Bu, \& Cai, 2021). Kreativitas karyawan dalam sebuah organisasi menjadi salah satu acuan untuk mengetahui apakah organisasi tersebut dapat memberikan performa dan kesuksesan yang diinginkan, karena kreativitas dianggap sebagai suatu keuntungan kompetitif bagi organisasi (Anderson, Potočnik, \& Zhou, 2014). Badan Usaha Milik Daerah (BUMD) PT. A menerapkan kreativitas sebagai salah satu nilai yang dianut dalam budaya kerja Madani, dimana nilai-nilai tersebut harus dianut oleh setiap karyawan maupun manajemen di PT. A. Dalam nilai budaya kerja Madani, perusahaan berusaha untuk dapat terus-menerus berkembang dan menjadi lebih modern dengan menggunakan kreativitas untuk melakukan berbagai pekerjaan maupun dalam pemecahan masalah (Bank Aceh, 2018). Kreativitas memungkinkan organisasi dan karyawannya untuk memunculkan ide, membuat dan mengembangkan metode kerja baru yang terdorong oleh banyaknya kemungkinan dari situasi yang tidak pasti, memanfaatkan kemungkinan ini dan menghasilkan metode serta praktik kerja baru (Hoffmann, Ivcevic, \& Brackett, 2016).

Kreativitas dapat diartikan sebagai produksi ide-ide atau solusi baru dan berguna dalam suatu proses maupun prosedur kerja untuk menyelesaikan masalah serta mencapai tujuan di organisasi (Amabile, 1983; George \& Zhou, 2001; Zhou \& Shalley, 2003). Karyawan dengan kreativitas tinggi mampu menggunakan beragam kemampuan dan keahlian, pengetahuan, pandangan, maupun pengalaman yang dimilikinya untuk mendapatkan ide baru guna memecahkan masalah, mengambil keputusan, atau menyelesaikan tugas dengan cara yang lebih efisien (Cheung \& Wong, 2011). Ide kreatif yang dikembangkan oleh karyawan juga dapat menjadi sumber daya yang berguna bagi organisasi untuk mampu berubah, tumbuh, bertahan, meningkatkan kinerja organisasi, dan memperoleh keuntungan serta kesuksesan (Wang et al., 2021). Chiang, Hsu, dan Hung (2014) menyebutkan bahwa kreativitas juga penting bagi inovasi serta untuk meningkatkan mental kompetisi pada karyawan di dalam perusahaan, dimana inovasi mengacu pada implementasi dari ide-ide kreatif (Mehta, Chandani, \& Neeraja, 
2014). Pada level organisasi, karyawan yang kreatif juga dapat meningkatkan inovasi dan peningkatan daya saing dari organisasi (Wang \& Wu, 2012).

Para peneliti telah mengusulkan core self-evaluation (CSE) sebagai prediktor yang patut dipertimbangkan dalam meneliti kreativitas (Wang et al., 2021; Zhang et al., 2020; Judge \& Kammeyer-Mueller, 2011). Dimana CSE merupakan salah satu bentuk karakteristik pribadi yang memiliki peran penting dalam menentukan kreativitas karyawan (Wang et al., 2021). CSE dapat diartikan sebagai penilaian dasar fundamental individu mengenai kemampuan, kompetensi, dan nilai-nilai yang ada pada dirinya sendiri (Judge, Erez, \& Bono, 1998). Penilaian dasar ini tetap stabil sepanjang waktu maupun pada situasi yang berbeda-beda (Chiang et al., 2014). Dibandingkan dengan konstruk kepribadian lainnya, CSE dinilai sebagai faktor personal dan merupakan konsep kepribadian yang lebih luas dan integratif dalam mengukur outcome yang berhubungan dengan pekerjaan (Zhang et al., 2020). Hal ini menjadikan CSE dianggap lebih baik dalam mengukur kreativitas karyawan.

Aktivitas yang berhubungan dengan kreativitas dianggap tidak pasti, karena tidak dapat menjamin hasil yang diinginkan (Zhou \& George, 2001), sehingga diperlukan kemauan kuat untuk mengambil resiko dan mengejar hasil positif yang penting untuk memunculkan kreativitas (Dewett, 2006). Penelitian menunjukkan bahwa individu dengan tingkat CSE yang tinggi memiliki keinginan kuat untuk mengembangkan kompetensi dan penguasaan tugas dalam mengejar hasil yang positif (Ferris et al., 2011). Meskipun penelitian sebelumnya telah menemukan bahwa CSE berhubungan positif dengan performa di tempat kerja (Chang et al., 2012; Ferris et al., 2011), kreativitas dianggap sebagai dimensi yang berbeda dari performa di tempat kerja (Madjar, Greenberg, \& Chen, 2011). Hal ini menjadikan perlu adanya penelitian lebih lanjut mengenai hubungan CSE dengan kreativitas karyawan. Hingga saat ini juga belum banyak penelitian yang secara sistematis menguraikan dan menguji pengaruh dari CSE pada kreativitas di tempat kerja (Wang et al., 2021; Zhang et al., 2020). Untuk dapat meraih kesuksesan dan mampu bertahan dalam jangka waktu yang lama, organisasi semakin bergantung pada kreativitas maupun inovasi yang dimiliki karyawannya (Anderson et al., 2014), sehingga menjadi penting untuk melakukan penelitian lebih lanjut mengenai hubungan CSE dengan kreativitas.

Penelitian terdahulu menemukan bahwa perlu adanya peran mediasi dari variabel lain untuk melihat hubungan antara CSE dengan kreativitas karyawan. Penelitian yang dilakukan oleh Chiang et al. (2014) yang menemukan bahwa karyawan dengan tingkat CSE tinggi terlibat dalam lebih banyak perilaku yang mampu menambah pengetahuan terkait pekerjaan dan lebih termotivasi secara intrinsik, serta secara positif terkait dengan kreativitas yang lebih tinggi. Wang et al. (2021) menemukan bahwa CSE mempengaruhi ketiga komponen individual intellectual capital (IIC), yaitu individual human capital (IHC), individual structural capital (ISC) dan individual relational capital (IRC), yang kemudian mempengaruhi kreativitas karyawan. Penelitian ini juga menemukan bahwa CSE memberikan lebih banyak pengaruh langsung pada incremental creativity dibandingkan pada radical creativity. Penelitian lainnya 
dilakukan oleh Zhang et al. (2020) yang menemukan bahwa perilaku berbagi pengetahuan antar karyawan berfungsi sebagai mekanisme yang menghubungkan CSE dengan kreativitas, serta ditemukan bahwa terdapat efek moderasi positif dari kebermaknaan kerja terhadap hubungan antara CSE dengan knowledge sharing.

Dengan menggunakan kerangka approach/avoidance (Chang et al., 2012; Elliot \& Thrash, 2002). Dalam kerangka ini dijelaskan bahwa individu memiliki kepekaan terhadap stimulus positif atau negatif (Elliot \& Thrash, 2002). Perbedaan kepekaan terhadap stimulus positif atau negatif ini mempengaruhi bagaimana individu mengevaluasi situasi sebagai menguntungkan atau merugikan (Ferguson \& Bargh, 2008), dan mengadopsi tujuan yang diarahkan untuk mengejar hasil positif (approach) atau menghindari hasil negatif (avoidance) (Elliot \& McGregor, 2001). Penelitian menunjukkan bahwa individu dengan tingkat CSE yang tinggi memiliki kecenderungan approach tinggi seperti kepribadian ekstrover, dan orientasi tujuan pembelajaran tingkat tinggi, yang mengacu pada keinginan seseorang untuk mengembangkan kompetensi dan penguasaan tugas dalam mengejar hasil yang positif (Ferris et al., 2011). Dengan demikian, individu yang memiliki tingkat CSE yang tinggi lebih tertarik untuk mencari lebih banyak aspek positif dari aktivitas yang berhubungan dengan kreativitas (Zhang et al., 2020).

Berdasarkan kerangka approach/avoidance ini, dapat dijelaskan bahwa individu dengan tingkat CSE yang tinggi memiliki keinginan untuk mengembangkan kompetensi dirinya, akan aktif bergerak dengan keinginan sendiri untuk melakukan pekerjaannya dengan cara mencari dan mengerjakan tugas-tugas yang menantang secara antusias dengan tujuan untuk meningkatkan kompetensi dirinya, sehingga ia menjadi kreatif. Dengan kata lain, individu dengan CSE yang tinggi akan memiliki motivasi intrinsik yang tinggi yang menjadi modal bagi kreativitasnya (Chiang et al., 2014; Ferris et al., 2011). Amabile (1996) mendefinisikan motivasi intrinsik sebagai keadaan ketika individu termotivasi dan berkomitmen pada pekerjaannya serta antusias untuk melakukan pekerjaan tersebut. Berdasarkan hal ini, peneliti menggunakan motivasi intrinsik sebagai mediator untuk meneliti hubungan tidak langsung antara CSE dengan kreativitas karyawan.

Kreativitas merupakan interaksi yang kompleks antara individu dan lingkungan (Amabile, 1996; Woodman \& Schoenfeldt, 1990). Lebih lanjut Woodman et al. (1993) menjelaskan kreativitas sebagai produk dari interaksi dinamis antara faktor individual dan faktor pengaturan sosial yang kompleks, dan menekankan pentingnya untuk mengidentifikasi serta memahami interaksi lintas tingkat untuk menjelaskan faktor yang dapat meningkatkan atau menghambat kreativitas. Faktor individu dan lingkungan tersebut merupakan salah satu interaksi yang paling penting dalam kreativitas karyawan, namun masih kurang dieksplorasi oleh penelitian sebelumnya yang jarang melihat efek gabungan dari kedua faktor ini (Jeong, McLean, McLean, Yoo, \& Bartlett, 2017). Salah satu faktor lingkungan atau sosial yang kompleks adalah budaya organisasi. Liu et al. (2016) dalam penelitiannya menyarankan untuk menginvestigasi peran moderator pada hubungan antara motivasi intrinsik dengan kreativitas karyawan, karena memiliki 
motivasi intrinsik saja tidak cukup untuk membuat individu menjadi kreatif (Amabile, 1983). Sebagai mekanisme motivasi, motivasi intrinsik dianggap sebagai pendorong utama kreativitas, namun penelitian terdahulu telah menghasilkan temuan yang beragam (Anderson et al., 2014), menimbulkan pertanyaan tentang apakah motivasi intrinsik benar-benar bertindak sebagai kekuatan motivasi dalam mengarahkan dan mempertahankan kreativitas (Liu et al., 2016). Berdasarkan hal ini peneliti menggunakan budaya organisasi pembelajaran sebagai moderator dalam hubungan antara motivasi intrinsik dengan kreativitas karyawan

Penelitian ini bertujuan untuk menjawab saran penelitian sebelumnya dari Liu et al. (2016) yang menyarankan untuk melakukan investigasi peran moderator pada hubungan antara motivasi intrinsik dengan kreativitas karyawan, karena memiliki motivasi intrinsik saja tidak cukup untuk membuat individu menjadi kreatif (Amabile, 1983), serta menjawab saran penelitian sebelumnya untuk menggunakan variabel lingkungan yang dapat memunculkan kreativitas (Zhang et al., 2020). Penelitian ini juga mengikuti saran penelitian dari Chiang et al. (2014) untuk menggunakan faktor situasional bersamaan dengan faktor individual yang dapat mempengaruhi kreativitas karyawan. Lebih spesifik Chiang et al. (2014) menyarankan untuk menggunakan iklim atau budaya di organisasi. Untuk menjawab hal ini peneliti menggunakan budaya organisasi pembelajaran sebagai faktor situasional.

\section{A. Peran Mediasi Motivasi Intrinsik}

Penelitian ini menggunakan kerangka approach/avoidance (Chang et al., 2012; Elliot \& Thrash, 2002). Dalam kerangka ini dijelaskan bahwa individu memiliki kepekaan terhadap stimulus positif atau negatif (Elliot \& Thrash, 2002). Perbedaan kepekaan terhadap stimulus positif atau negatif ini mempengaruhi bagaimana individu mengevaluasi situasi sebagai menguntungkan atau merugikan (Ferguson \& Bargh, 2008), dan mengadopsi tujuan yang diarahkan untuk mengejar hasil positif (approach) atau menghindari hasil negatif (avoidance) (Elliot \& McGregor, 2001).

Dengan menggunakan kerangka approach/avoidance (Chang et al., 2012; Elliot \& Thrash, 2002), penelitian menunjukkan bahwa individu dengan tingkat CSE yang tinggi memiliki kecenderungan approach tinggi seperti kepribadian ekstrover, dan orientasi tujuan pembelajaran tingkat tinggi, yang mengacu pada keinginan seseorang untuk mengembangkan kompetensi dan penguasaan tugas dalam mengejar hasil yang positif (Ferris et al., 2011). Dengan demikian, individu yang memiliki tingkat CSE yang tinggi lebih tertarik untuk mencari lebih banyak aspek positif dari aktivitas yang berhubungan dengan kreativitas (Zhang et al., 2020). Individu dengan tingkat CSE yang rendah sebaliknya diketahui memiliki kemungkinan yang rendah untuk berbagi pengetahuan dibandingkan dengan individu dengan tingkat CSE tinggi, yang akhirnya akan menghambat kreativitas (Zhang et al., 2020).

Menggunakan teori approach avoidance dapat dijelaskan bahwa individu yang memiliki tingkat CSE yang tinggi akan merasa optimis dan mampu merasakan 
makna pekerjaannya secara positif sehingga merasa senang, puas dan antusias mengerjakan tugas-tugasnya, sehingga pada gilirannya ia dapat menampilkan perilaku kreatif. Dalam hal ini, motivasi intrinsik memediasi hubungan antara CSE dan kreativitas karyawan. Motivasi intrinsik menjadikan individu mampu untuk secara terus menerus terlibat dalam proses kreatif seperti mengusulkan ide-ide baru, serta percaya bahwa dirinya mampu untuk mencapai hasil yang kreatif (Liu et al., 2016). Memikirkan ide-ide baru dalam proses kreatif melibatkan identifikasi masalah, pencarian informasi, serta generasi ide-ide baru (Reiter-Palmon \& Illies, 2004). Individu yang termotivasi secara intrinsik akan mampu mencurahkan lebih banyak energi untuk mampu memecahkan masalah serta bertahan lebih lama dalam proses pemecahan masalah secara kreatif (Shalley, 1995). Individu dengan tingkat CSE tinggi juga lebih percaya diri dalam mencapai hasil positif (Judge \& Kammeyer-Mueller, 2011), serta lebih cenderung terlibat dalam perilaku kondusif yang dapat meningkatkan kreativitas (Y. Zhang et al., 2020) seperti melakukan kegiatan berdasarkan minat, memiliki rasa ingin tahu yang besar, dan keinginan untuk terus belajar.

Berdasarkan kerangka approach/avoidance ini, dapat disimpulkan bahwa bahwa individu dengan tingkat CSE yang tinggi memiliki kecenderungan untuk melakukan berbagai hal positif seperti mengembangkan kompetensi dirinya, aktif bergerak dengan keinginan sendiri untuk melakukan pekerjaannya dengan cara mencari dan mengerjakan tugas-tugas yang menantang secara antusias dengan tujuan untuk meningkatkan kompetensi dirinya, sehingga ia menjadi kreatif. Dengan kata lain, individu dengan CSE yang tinggi akan memiliki motivasi intrinsik yang tinggi yang menjadi modal bagi kreativitasnya (Chiang et al., 2014; Ferris et al., 2011).

Hipotesis 1 (H1): CSE berhubungan tidak langsung dengan kreativitas karyawan melalui motivasi intrinsik.

\section{B. Peran Moderasi Budaya Organisasi Pembelajaran}

Penelitian ini akan melihat peran moderasi budaya organisasi pembelajaran sebagai faktor lingkungan pada hubungan antara motivasi intrinsik sebagai faktor individu dengan kreativitas karyawan. Variabel ini digunakan karena budaya organisasi dapat meningkatkan hasil organisasi yang positif (Hahn et al., 2015; Tran \& Pham, 2019). Teori information-processing digunakan untuk menjelaskan peran moderator dari budaya organisasi pembelajaran. Teori information-processing mengasumsikan bahwa banyak aspek dalam perilaku dan pengalaman manusia dapat dipahami dengan melihat bagaimana informasi dari berbagai sumber internal maupun eksternal diproses (Crick \& Dodge, 1994). Pemrosesan informasi mengacu kepada bagaimana individu mengumpulkan atau menerima stimulus dari lingkungan, mengorganisasi informasi yang diperoleh, serta menggunakannya untuk bertindak, atau memecahkan masalah (Crick \& Dodge, 1994).

Memikirkan ide-ide baru di tempat kerja mengharuskan individu untuk berusaha dalam proses pemecahan masalah kreatif, yang melibatkan tiga komponen 
yaitu identifikasi masalah, pencarian informasi, dan pembentukan ide (ReiterPalmon \& Illies, 2004). Individu akan memiliki kesempatan yang lebih baik untuk memikirkan ide-ide baru dan berguna ketika individu mencurahkan lebih banyak energi untuk mengidentifikasi masalah dari berbagai perspektif, mengumpulkan informasi yang beragam tetapi relevan untuk memecahkan masalah, dan menghasilkan berbagai solusi alternatif (Zhang \& Bartol, 2010). Organisasi yang memiliki budaya organisasi pembelajaran mampu dalam membuat, mendapatkan, melakukan transfer ilmu, serta memodifikasi perilaku karyawannya untuk merefleksikan ilmu dan ide baru (Garvin, 1993) yang merupakan proses kreatif. Budaya organisasi pembelajaran juga mendukung pandangan dan eksperimen unik yang dilakukan karyawannya, mendorong kolaborasi untuk melakukan transfer ilmu, dan memberdayakan karyawan untuk dapat mencapai visi organisasi (Marsick \& Watkins, 2003). Organisasi yang mempunya budaya pembelajaran diketahui memiliki karakteristik yang kondusif untuk meningkatkan kreativitas karyawan, dimana organisasi seperti ini memiliki orientasi terhadap intelektual, kebebasan, pengambilan risiko, dukungan terhadap tugas, penerimaan atas ketidakpastian, komunikasi yang terbuka, kolaborasi, dan penghargaan (McLean, 2005; Shalley \& Gilson, 2004). Kreativitas membutuhkan proses trial-and-error untuk memperoleh pengetahuan baru (Jeong et al., 2017) yang akan didukung dengan adanya budaya pembelajaran dalam organisasi. Choi (2020) menjelaskan bahwa budaya organisasi pembelajaran dapat meningkatkan kreativitas karyawan.

Dengan demikian, budaya organisasi pembelajaran memoderasi hubungan antara motivasi intrinsik dan kreativitas karyawan, dimana individu yang mempersepsikan organisasinya memiliki budaya pembelajaran yang tinggi dan pada saat yang bersamaan memiliki motivasi intrinsik yang tinggi akan menampilkan kreativitas. Sebaliknya, individu memiliki motivasi intrinsik yang tinggi tetapi ia mempersepsikan organisasinya memiliki budaya pembelajaran yang rendah, cenderung akan menurunkan tingkat kreativitasnya. Sejalan dengan hal tersebut di atas, jika budaya organisasi pembelajaran dapat memoderasi hubungan antara motivasi intrinsik dan kreativitas karyawan, maka budaya organisasi pembelajaran juga memoderasi hubungan tidak langsung antara CSE dan kreativitas karyawan melalui motivasi intrinsik.

Hipotesis 2 (H2): Hubungan antara motivasi intrinsik dengan kreativitas karyawan akan diperkuat saat budaya organisasi pembelajaran tinggi, dan melemah saat budaya organisasi pembelajaran rendah.

Hipotesis 3 (H3): Hubungan tidak langsung antara CSE dengan kreativitas karyawan dimediasi oleh motivasi intrinsik, serta budaya organisasi pembelajaran memoderasi hubungan antara motivasi intrinsik dengan kreativitas karyawan. 


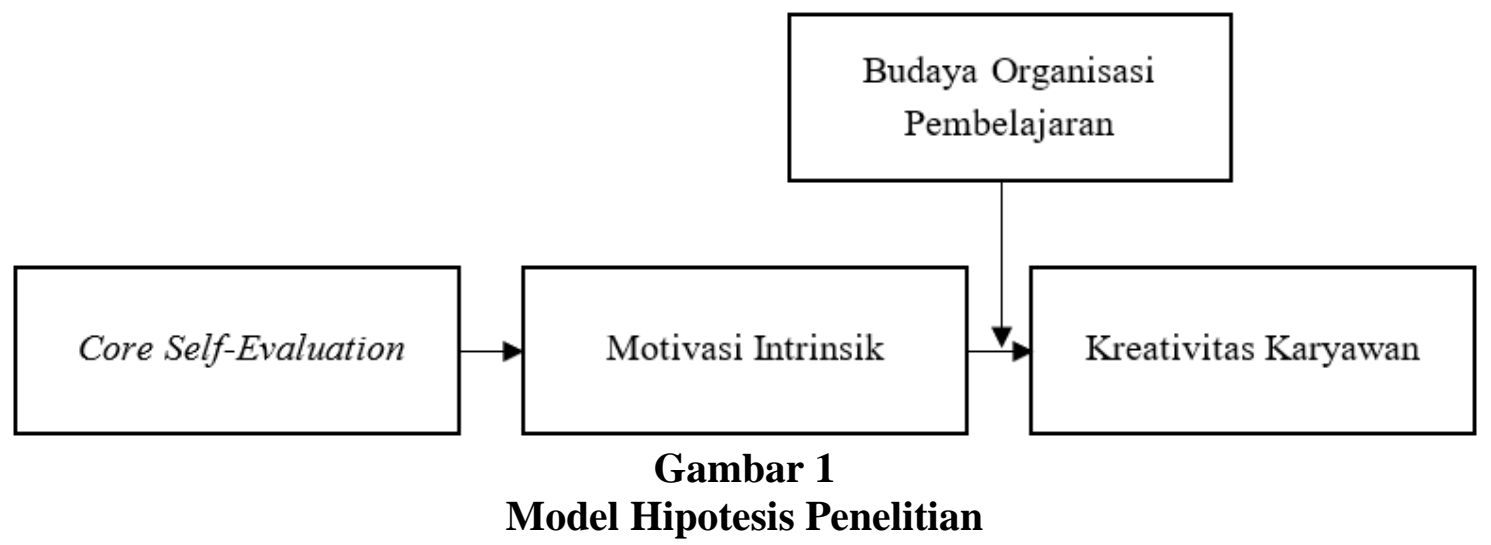

\section{Metode Penelitian}

Desain penelitian yang digunakan adalah non-experimental (korelasional) pada sebuah perusahaan Badan Usaha Milik Daerah (BUMD) di Indonesia, menggunakan survei daring melalui Google form. Kuesioner disebar dengan bantuan tim Sumber Daya Manusia (SDM) perusahaan tempat pengambilan data melalui grup Whatsapp perusahaan kepada karyawan yang sesuai dengan kriteria responden penelitian. Pendekatan cross-sectional digunakan dengan melakukan pengambilan data dalam satu waktu.

Tabel 1

Demografi Sampel Penelitian

\begin{tabular}{lcc}
\hline Karakteristik Demografi & Jumlah & $\mathbf{\%}$ \\
\hline Jenis Kelamin & & \\
$\quad$ Laki-laki & 113 & $78,5 \%$ \\
$\quad$ Perempuan & 31 & $21,5 \%$ \\
Usia & & \\
$\quad$ < 30 Tahun & 25 & $17,4 \%$ \\
31 - 40 Tahun & 88 & $61,1 \%$ \\
$\quad$ > 41 Tahun & 31 & $21,5 \%$ \\
Pendidikan & & \\
$\quad$ SMA Sederajat & 16 & $11,1 \%$ \\
$\quad$ Diploma & 13 & $9 \%$ \\
$\quad$ Sarjana & 100 & $69,4 \%$ \\
$\quad$ Pascasarjana & 15 & $10,4 \%$ \\
Masa Kerja & & \\
$\quad$ < 5 Tahun & 16 & $11,1 \%$ \\
$\quad$ - 10 Tahun & 53 & $36,8 \%$ \\
$\quad>10$ Tahun & 75 & $52,1 \%$ \\
\hline N = 144 & &
\end{tabular}

Prosedur pemilihan sampel dilakukan dengan purposive sampling dimana sampel diambil berdasarkan kriteria yang ditetapkan sesuai tujuan penelitian (Cozby \& Bates, 2011). Peneliti menggunakan karakteristik karyawan yang bekerja minimal selama satu tahun karena masa kerja diketahui dapat mempengaruhi kreativitas karyawan (Kim, 2019). Berdasarkan hasil korelasi antara CSE dengan kreativitas pada penelitian Zhang et al. (2020) dengan nilai $\mathrm{r}=0,26, p<.01$, peneliti memperoleh hasil effect size 
menggunakan bantuan aplikasi Gpower 3.1 untuk jumlah sampel penelitian sebanyak 144 karyawan. Demografi sampel penelitian dapat dilihat pada tabel 1.

Kreativitas karyawan diukur menggunakan alat ukur self-report dari Zhou dan George (2001) yang kemudian diadaptasi oleh Hahn et al. (2015) terdiri dari 4 aitem dengan nilai reliabilitas $\alpha=0,86$. karyawan memberikan penilaian terhadap dirinya dalam format skala Likert 5 poin dari 5 poin dari B1 (sangat tidak setuju) sampai B5 (sangat setuju).

CSE diukur menggunakan alat ukur The Core Self-Evaluation Scale yang disusun oleh Judge et al. (2003). Alat ukur berbentuk self-report ini terdiri dari 12 aitem dengan nilai reliabilitas $\alpha=0,76$. Karyawan memberikan penilaian terhadap dirinya dalam format respon skala Likert 5 poin yang terdiri dari 1 (sangat tidak setuju) sampai 5 (sangat setuju).

Motivasi intrinsik diukur menggunakan alat ukur yang dikembangkan oleh Tierney et al. (1999). Alat ukur ini berbentuk self-report yang terdiri dari 5 aitem dengan nilai reliabilitas $\alpha=0,82$. Karyawan memberikan penilaian terhadap dirinya dalam format respon skala Likert 6 poin dari 1 (sangat tidak setuju) sampai 6 (sangat setuju).

Budaya organisasi pembelajaran diukur menggunakan alat ukur self-report Dimension of Learning Organization Questionnaire (DLOQ) yang dikembangkan oleh Marsick dan Watkins (2003). Alat ukur ini terdiri dari 7 aitem serta memiliki nilai reliabilitas $\alpha=0,87$. Karyawan memberikan penilaian terhadap perusahaannya dirinya dalam format respon skala Likert 6 poin dari 1 (hampir tidak benar) sampai 6 (hampir sangat benar). Seluruh alat ukur yang digunakan telah melalui proses adaptasi dari bahasa asalnya ke bahasa Indonesia.

Peneliti melakukan kontrol terhadap variabel demografis dalam penelitian ini. Variabel demografis yang dikontrol diantaranya adalah jenis kelamin, usia, pendidikan terakhir, dan masa kerja. Keempat variabel ini memiliki hubungan yang signifikan yang dapat mempengaruhi kreativitas karyawan (Kim, 2019). Usia dan latar pendidikan juga diketahui dapat mempengaruhi keinginan individu untuk belajar yang akhirnya akan mempengaruhi kreativitas yang ditunjukkan oleh individu (Jones \& Weinberg, 2011).

Peneliti menggunakan analisis moderated mediation (Hayes, 2018) PROCESS Model 14 untuk melakukan uji hipotesis. Seluruh analisis dalam penelitian ini dilakukan menggunakan bantuan software SPSS versi 25 .

\section{Hasil dan Pembahasan}

Hasil uji korelasi antar variabel menunjukkan bahwa kreativitas karyawan berhubungan positif signifikan dengan CSE $(r=0,36, p<0,01)$, motivasi intrinsik $(r=$ $0,59, p<0,01)$, dan budaya organisasi pembelajaran $(r=0,42, p<0,01)$. CSE diketahui juga berhubungan positif signifikan lemah dengan motivasi intrinsik $(r=0,20, p<$ $0,01)$, serta budaya organisasi pembelajaran berhubungan positif signifikan lemah dengan motivasi intrinsik $(r=0,20, p<0,01)$. 
Hasil uji korelasi juga menunjukkan bahwa variabel kreativitas karyawan tidak berkorelasi dengan variabel demografi jenis kelamin $(r=-0,06 ; p<0,01)$, usia $(r=-$ $0,05 ; \mathrm{p}<0,01)$, dan pendidikan $(\mathrm{r}=-0,04 ; \mathrm{p}<0,01)$. Sedangkan masa kerja $(\mathrm{r}=-0,23 ; \mathrm{p}$ $<0,01)$ berkorelasi negatif dengan kreativitas karyawan. Mean, standar deviasi, dan korelasi lebih lanjut dapat dilihat pada tabel 2.

Tabel 2

\begin{tabular}{|c|c|c|c|c|c|c|c|c|c|c|}
\hline \multicolumn{11}{|c|}{ Korelasi Antar Variabel } \\
\hline Variabel & M & SD & 1 & 2 & 3 & 4 & 5 & 6 & 7 & 8 \\
\hline 1. Jenis Kelamin & 1,22 & 0,41 & 1 & & & & & & & \\
\hline 2. Usia & 2,04 & 0,62 & $\overline{-}$ & 1 & & & & & & \\
\hline 3. Pendidikan & 2,79 & 0,77 & 0,14 & $\begin{array}{c}- \\
0,30 * *\end{array}$ & 1 & & & & & \\
\hline 4. Masa Kerja & 2,41 & 0,68 & 0,03 & $0,53 * *$ & $\begin{array}{c}- \\
0,11\end{array}$ & 1 & & & & \\
\hline 5. CSE & 4,26 & 0,52 & $\overline{0}, 00$ & $-0,07$ & 0,01 & 0,00 & 1 & & & \\
\hline $\begin{array}{l}\text { 6. Motivasi } \\
\text { intrinsik }\end{array}$ & 4,93 & 0,69 & $\overline{-}, 02$ & 0,01 & $0,-$ & $-0,05$ & $0,20 *$ & 1 & & \\
\hline $\begin{array}{l}\text { 7. Budaya } \\
\text { organisasi } \\
\text { pembelajaran }\end{array}$ & 5,10 & 0,72 & $\overline{-}, 06$ & $0,19 *$ & $0, \overline{16}$ & 0,12 & $0,30 * *$ & $0,24 * *$ & 1 & \\
\hline $\begin{array}{l}\text { 8. Kreativitas } \\
\text { karyawan }\end{array}$ & 3,87 & 0,62 & $\begin{array}{c}- \\
0,06\end{array}$ & $-0,05$ & $\overline{-}, 04$ & $\begin{array}{c}- \\
0,23 * *\end{array}$ & $0,36 * *$ & $0,59 * *$ & $0,42 * *$ & \\
\hline
\end{tabular}

Keterangan: $\mathrm{N}=144$. Kode jenis kelamin $=1$ (laki-laki) dan 2 (perempuan). Kode Usia = 1 (30 tahun ke bawah), 2 (31 - 40 tahun), dan 3 (41 tahun ke atas). Kode pendidikan terakhir $=1$ (SMA atau sederajat), 2 (Diploma), 3 (Sarjana), dan 4 (Pascasarjana). Kode masa kerja $=1$ ( $<5$ tahun), 2 (5 - 10 tahun), dan 3 ( $>10$ tahun). ${ }^{*} p<0,05 . * * p<0,01$.

Sebelum melakukan uji asumsi, peneliti terlebih dahulu melakukan analisis Harman's Single Factor Test untuk melihat sejauh mana common method bias mempengaruhi penelitian. Hasil menunjukkan nilai sebesar $24,30 \%$ yang menunjukkan bahwa tidak terdapat common method bias dalam penelitian ini (Podsakoff, MacKenzie, Lee, \& Podsakoff, 2003).

Berikutnya uji multikolinearitas dilakukan untuk melihat ada atau tidaknya korelasi yang tinggi antara variabel dalam model regresi melalui nilai Tolerance dan Variance Inflation Factor (VIF). Suatu model regresi dikatakan memiliki multikolinearitas jika nilai Tolerance lebih besar dari 0,10 dan nilai VIF lebih kecil dari 10. Tabel 3 menyajikan hasil uji multikolinearitas yang menunjukkan bahwa nilai tolerance CSE $(0,89>0,10)$, motivasi intrinsik $(0,92>0,10)$, dan budaya organisasi pembelajaran $(0,87>0,10)$, sedangkan nilai VIF CSE $(1,12<10)$, motivasi intrinsik $(1,08<10)$, dan budaya organisasi pembelajaran $(1,14<10)$ tidak terdapat multikolinearitas dalam model regresi penelitian. 
Intrinsik

Tabel 3

Uji Multikolinearitas

\begin{tabular}{|c|c|c|c|c|c|c|c|c|}
\hline \multirow[b]{2}{*}{ Model } & & \multicolumn{2}{|c|}{$\begin{array}{l}\text { Unstandardized } \\
\text { Coefficients }\end{array}$} & \multirow{2}{*}{$\begin{array}{c}\text { Standardized } \\
\text { Coefficients } \\
\text { Beta }\end{array}$} & \multirow[b]{2}{*}{$\mathbf{t}$} & \multirow[b]{2}{*}{ Sig. } & \multicolumn{2}{|c|}{$\begin{array}{c}\text { Collinearity } \\
\text { Statistics }\end{array}$} \\
\hline & & B & $\begin{array}{l}\text { Std. } \\
\text { error }\end{array}$ & & & & Tolerance & VIF \\
\hline \multirow[t]{4}{*}{1} & (Constant) & $-0,40$ & 0,40 & & $-0,99$ & 0,32 & & \\
\hline & CSE & 0,22 & 0,07 & 0,19 & 2,94 & 0,00 & 0,89 & 1,12 \\
\hline & $\begin{array}{l}\text { Motivasi } \\
\text { intrinsik }\end{array}$ & 0,45 & 0,05 & 0,49 & 7,74 & 0,00 & 0,92 & 1,08 \\
\hline & $\begin{array}{l}\text { Budaya } \\
\text { organisasi } \\
\text { pembelajaran }\end{array}$ & 0,21 & 0,05 & 0,24 & 3,72 & 0,00 & 0,87 & 1,14 \\
\hline
\end{tabular}

a. Dependent Variable: Kreativitas Karyawan

Tabel 3 menunjukkan hasil analisis terhadap variabel kontrol menunjukkan bahwa variabel demografi masa kerja memprediksi kreativitas karyawan secara negatif dan signifikan $(b=-0,26, S E=0,06, p<0,001)$. Hal ini mengindikasikan karyawan dengan masa kerja yang lebih lama menjadi kurang kreatif dibandingkan dengan karyawan dengan masa kerja yang lebih singkat. Jenis kelamin, usia, dan pendidikan ditemukan tidak memprediksi kreativitas karyawan secara signifikan $(b=-0,03, S E=$ $0,09, p=0,775 ; b=-0,06, S E=0,07, p=0,423 ; b=-0,05, S E=0,05, p=0,350$, secara berurutan).

\section{Tabel 4}

Uji Hipotesis

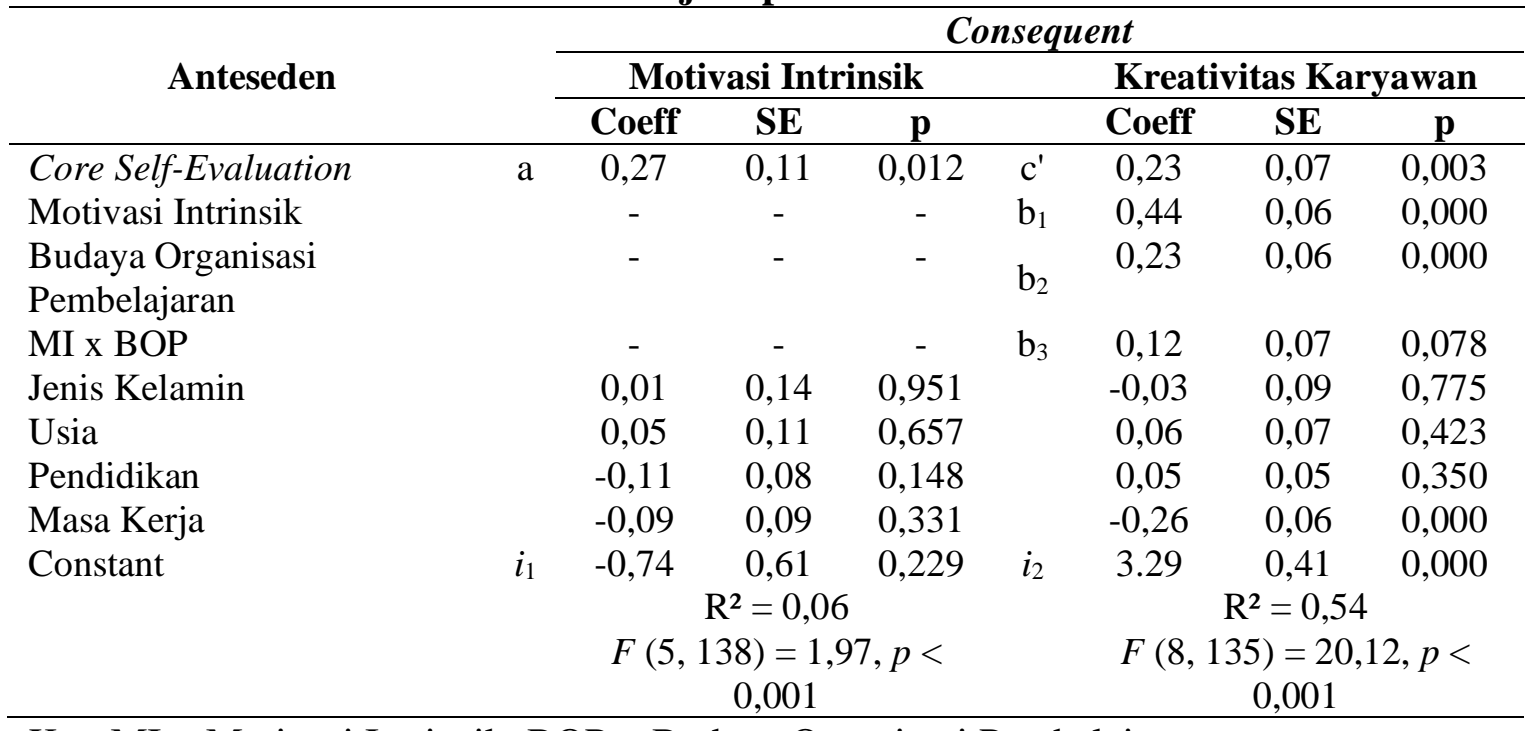

Ket: $\mathrm{MI}=$ Motivasi Intrinsik, $\mathrm{BOP}=$ Budaya Organisasi Pembelajaran.

Tabel 4 juga menunjukkan CSE memprediksi kreativitas karyawan secara positif dan signifikan $(b=0,23, S E=0,07, p=0,003)$. Hal ini mengindikasikan karyawan dengan CSE yang tinggi akan menampilkan kreativitas. Motivasi intrinsik diketahui juga memprediksi kreativitas karyawan secara positif dan signifikan $(b=0,44, S E=$ 
$0,06, p=0,000)$ yang mengindikasikan bahwa karyawan dengan tingkat motivasi intrinsik yang tinggi akan menampilkan kreativitas. Budaya organisasi pembelajaran juga mampu memprediksi kreativitas karyawan secara positif dan signifikan $(b=0,23$, $S E=0,06, p=0,000)$. Hal ini menunjukkan bahwa karyawan dengan organisasi yang mempunyai budaya organisasi pembelajaran tinggi akan menampilkan kreativitas.

Hasil analisis Tabel 4 secara umum menunjukkan bahwa CSE, motivasi intrinsik, budaya organisasi pembelajaran dan masa kerja secara signifikan mampu memprediksi kreativitas karyawan dengan nilai $F(8,135)=20,12, p<0,01, R^{2}=0,54$. Dengan demikian sebanyak $54 \%$ dari kedua prediktor secara signifikan mampu menjelaskan kreativitas karyawan.

Tabel 5 menunjukkan indirect effect dari CSE ke kreativitas karyawan melalui budaya organisasi pembelajaran signifikan pada $\mathrm{SD}=0$ (indirect effect $=0,12, S E=$ $0,05,95 \%$ CI $[0,02 ; 0,24])$. Dengan demikian, Hipotesis 1 yang menyatakan bahwa motivasi intrinsik memediasi hubungan antara CSE dan kreativitas karyawan, didukung oleh data Hasil analisis Tabel 4 juga menunjukkan bahwa tidak ada peran moderasi dari budaya organisasi pembelajaran terhadap motivasi intrinsik dengan kreativitas karyawan $(b=0,12, p=0,07$, CI $[-0,01,0,25])$, dengan demikian Hipotesis 2 yang menyatakan bahwa budaya organisasi pembelajaran memoderasi hubungan antara motivasi intrinsik dan kreativitas karyawan tidak didukung oleh data.

\section{Tabel 5}

Conditional Indirect Effect

\begin{tabular}{|c|c|c|c|c|}
\hline \multicolumn{2}{|c|}{ Budaya Organisasi Pembelajaran } & B & SE & $95 \%$ CI \\
\hline \multicolumn{5}{|c|}{$\mathrm{CSE} \rightarrow \mathrm{MI} \rightarrow \mathrm{KK}$} \\
\hline -1SD (Rendah) & $-0,73$ & 0,09 & 0,05 & {$[0,01,0,19]$} \\
\hline M (Sedang) & 0,00 & 0,12 & 0,05 & {$[0,02,0,24]$} \\
\hline$+1 \mathrm{SD}$ (Tinggi) & 0,73 & 0,14 & 0,07 & {$[0,02,0,29]$} \\
\hline Index of Moderate & & 0,03 & 0,03 & {$[-0,00,0,11]$} \\
\hline
\end{tabular}

Ket: $\overline{\mathrm{CSE}}=$ Core Self-Evaluation, $\mathrm{MI}=$ Motivasi Intrinsik, KK = Kreativitas karyawan

Hasil analisis conditional indirect effect menggunakan analisis moderated mediation PROCESS Model 14 pada tabel 5 menunjukkan hubungan tidak langsung antara CSE dengan kreativitas karyawan melalui peran mediasi motivasi intrinsik berdasarkan tingkatan budaya organisasi pembelajaran rendah, sedang, dan tinggi. Hasil analisis menunjukkan bahwa hubungan tidak langsung antara CSE dengan kreativitas karyawan melalui motivasi intrinsik tetap signifikan pada semua tingkatan budaya organisasi pembelajaran (rendah $b=0,09$, CI $[0,01,0,19]$; sedang $b=0,12$, CI [0,02, $0,24]$; dan tinggi $b=0,14$, CI [0,02, 0,29]). Index of moderated mediation ( $b=0,03, \mathrm{CI}$ $[-0,00,0,11])$ pun tidak signifikan. Dengan demikian, Hipotesis 3 yang menyatakan bahwa budaya organisasi pembelajaran memoderasi hubungan antara CSE dan kreativitas karyawan tidak didukung oleh data.

Hasil dari penelitian ini menunjukkan bahwa motivasi intrinsik memediasi hubungan antara CSE dengan kreativitas karyawan. Dengan kata lain karyawan yang memiliki CSE akan lebih terinspirasi dan meningkatkan motivasi intrinsiknya untuk 
melakukan pekerjaannya yang secara tidak langsung menjadikan karyawan tersebut lebih termotivasi untuk memberikan ide-ide atau menemukan cara yang lebih baik untuk mengatasi permasalahan kerjanya. Hal ini sesuai dengan penelitian yang dilakukan oleh Chiang et al. (2014) dan Zhang et al. (2020) dimana CSE berhubungan tidak langsung dengan kreativitas karyawan.

Terdapat perbedaan dari penelitian ini dibandingkan dengan Chiang et al. (2014) dan Zhang et al. (2020) yang menggunakan responden dari bidang yang cenderung membutuhkan kreativitas. Penelitian ini menggunakan responden dari BUMD dengan budaya kerja birokratif yang cenderung tidak mendukung kreativitas (Hirst, Van Knippenberg, Chen, \& Sacramento, 2011). Hasil penelitian menunjukkan bahwa kreativitas karyawan pada PT. A cenderung tinggi. Hal ini dapat disebabkan karena adanya nilai budaya kerja Madani yang dianut. Dalam nilai Madani ini perusahaan berusaha untuk dapat terus-menerus berkembang dan menjadi lebih modern dengan menggunakan kreativitas untuk melakukan berbagai pekerjaan maupun dalam pemecahan masalah (Bank Aceh, 2018). Dengan adanya nilai Madani PT. A mendorong karyawannya untuk menggunakan kreativitas, yang pada akhirnya menjadikan karyawannya cenderung memiliki kreativitas yang tinggi.

Menggunakan landasan teori approach/avoidance framework (Chang et al., 2012; Elliot \& Thrash, 2002) yang menjelaskan bahwa pengalaman individu dapat diklasifikasikan kedalam kepekaannya terhadap informasi positif atau negatif (Elliot, 1999), penelitian ini membuktikan bahwa karyawan dengan tingkat CSE yang tinggi memiliki temperamen approach tinggi seperti kepribadian ekstrover, dan orientasi tujuan pembelajaran tingkat tinggi, yang mengacu pada keinginan individu untuk mengembangkan kompetensi dan penguasaan tugas untuk mengejar hasil yang positif (Ferris et al., 2011). Karyawan dengan tingkat CSE tinggi lebih termotivasi untuk secara aktif mencapai performa yang baik di tempat kerja (Chiang et al., 2014; Ferris et al., 2011). Karyawan dengan tingkat CSE yang tinggi akan lebih termotivasi secara intrinsik, menikmati dan menganggap pekerjaan yang dilakukannya menyenangkan, serta secara aktif dan otonom mengejar hasil positif Chiang et al. (2014). Individu dengan tingkat CSE yang tinggi juga memiliki keinginan untuk mengembangkan kompetensi dirinya, akan aktif bergerak dengan keinginan sendiri untuk melakukan pekerjaannya dengan cara mencari dan mengerjakan tugas-tugas yang menantang secara antusias dengan tujuan untuk meningkatkan kompetensi dirinya, sehingga lebih mampu melihat banyak aspek positif dari kegiatan yang berhubungan dengan kreativitas Zhang et al. (2020). Dengan kata lain, individu dengan CSE yang tinggi akan memiliki motivasi intrinsik yang tinggi yang menjadi modal bagi kreativitasnya (Chiang et al., 2014; Ferris et al., 2011).

CSE diketahui memiliki empat komponen, diantaranya adalah generalized selfefficacy, self esteem, stabilitas emosi dan locus of control (Judge et al., 2003). Tingginya generalized self-efficacy dan locus of control menjadikan karyawan tersebut merasa dirinya mampu melakukan berbagai tugas yang berhubungan dengan kreativitas, serta meyakini kreativitas yang dimilikinya merupakan dampak dari dirinya sendiri, 
bukan dari lingkungannya sehingga meningkatkan motivasi intrinsik pada dirinya. tingginya self-esteem dan stabilitas emosi juga menjadikan individu percaya bahwa dirinya mampu untuk melakukan pekerjaannya dengan baik dan stabil secara emosi, yang pada akhirnya membantu karyawan untuk terus menerus terlibat dalam kegiatan yang berhubungan dengan kreativitas dan menemukan pemecahan masalah yang kreatif. Ide-ide kreatif yang dimiliki oleh karyawan pada akhirnya dapat diimplementasikan untuk memunculkan inovasi (Mehta et al., 2014). Dimana kreativitas dan inovasi mendorong kemajuan dan memungkinkan organisasi untuk mempertahankan keunggulan kompetitif. meningkatkan daya saing (Wang \& Wu, 2012).

Hasil penelitian ini juga menemukan bahwa direct effect CSE pada kreativitas karyawan masih signifikan setelah mediator masuk ke dalam persamaan regresi. Hal ini ini menunjukkan bahwa terdapat varians dari CSE terhadap kreativitas yang tidak dapat dijelaskan oleh motivasi intrinsik. Peneliti memperkirakan varians dari CSE ke kreativitas karyawan yang tidak bisa diterjemahkan oleh motivasi intrinsik adalah yang terkait dengan stabilitas emosi dan kontrol pada penyelesaian tugas, karena motivasi intrinsik lebih berfokus pada kegembiraan dan kepuasan karena memiliki tugas-tugas yang menantang. Namun demikian, motivasi intrinsik tetap memiliki hubungan yang lebih dekat dengan kreativitas dibandingkan dengan CSE dan kreativitas.

Penelitian ini juga mengikuti saran penelitian dari Chiang et al. (2014) untuk menggunakan faktor situasional bersamaan dengan faktor individual yang dapat mempengaruhi kreativitas karyawan. Lebih spesifik Chiang et al. (2014) menyarankan untuk menggunakan iklim atau budaya di organisasi. Untuk menjawab hal ini peneliti menggunakan budaya organisasi pembelajaran sebagai faktor situasional. Hasil penelitian menemukan bahwa budaya organisasi pembelajaran sebagai moderator tidak memiliki pengaruh dalam meningkatkan atau melemahkan hubungan antara motivasi intrinsik dengan kreativitas karyawan. Sebagai konsekuensi dari tidak signifikannya peran moderasi budaya organisasi pembelajaran pada hubungan antara motivasi intrinsik dan kreativitas karyawan, maka budaya organisasi pembelajaran juga tidak signifikan memoderasi hubungan tidak langsung antara CSE dan kreativitas karyawan melalui motivasi intrinsik. Meskipun budaya organisasi pembelajaran mampu mendorong pandangan dan eksperimen unik dari karyawan, serta kolaborasi dalam berbagi pengetahuan (Marsick \& Watkins, 2003) yang akhirnya dapat meningkatkan kreativitas karyawan (Song, Chermack, \& Kim, 2013), motivasi intrinsik juga dapat mendorong keinginan untuk menjadi kreatif (Amabile, 1996). Motivasi intrinsik menjadikan individu mampu untuk secara terus menerus terlibat dalam proses kreatif seperti mengusulkan ide-ide baru, serta percaya bahwa dirinya mampu untuk mencapai hasil yang kreatif (Liu et al., 2016). Memikirkan ide-ide baru dalam proses kreatif melibatkan identifikasi masalah, pencarian informasi, serta generasi ide-ide baru (Reiter-Palmon \& Illies, 2004). Individu yang termotivasi secara intrinsik akan mampu mencurahkan lebih banyak energi untuk mampu memecahkan masalah serta bertahan lebih lama dalam proses pemecahan masalah secara kreatif (Shalley, 1995). Berdasarkan hal ini peneliti berargumen bahwa individu yang termotivasi secara 
intrinsik dalam pekerjaannya, tidak terpengaruh oleh lingkungannya untuk dapat mencapai hasil yang kreatif. Hasil ini sejalan dengan hasil penelitian Jeong et al. (2017) yang menemukan bahwa budaya organisasi pembelajaran tidak memiliki pengaruh yang signifikan sebagai moderator terhadap hubungan antara domain expertise dan creative personality dengan kreativitas karyawan. Hasil ini juga dapat disebabkan oleh permasalahan teknis seperti sedikitnya responden penelitian yang digunakan. Jumlah responden yang cenderung sedikit kurang memiliki statistical power dalam mendeteksi efek moderasi dari budaya organisasi pembelajaran (Memon et al., 2019).

Berbeda dengan hasil yang ditemukan oleh Jones dan Weinberg (2011), Kim (2019), serta Shalley dan Gilson (2004), penelitian ini menemukan bahwa jenis kelamin, usia, dan pendidikan tidak mempengaruhi kreativitas. Variabel demografi masa kerja disisi lain memiliki pengaruh negatif signifikan terhadap kreativitas karyawan, sejalan dengan hasil yang ditemukan oleh Jones dan Weinberg (2011), Kim (2019), serta Shalley dan Gilson (2004). Hal ini menunjukkan bahwa semakin lama masa kerja karyawan, semakin rendah kreativitas yang dimilikinya. Hal ini dapat disebabkan karena budaya kerja BUMD yang sudah baku dalam pola kerja birokrasi (Badan Pengawasan Keuangan dan Pembangunan, 2014). Pola kerja birokrasi yang sudah baku menjadikan setiap pekerjaan yang ada sudah memiliki tata cara tersendiri sehingga karyawan terbiasa melakukan pekerjaan dengan pola atau tata cara yang sudah sering digunakan. Sedangkan karyawan dengan masa kerja yang lebih baru cenderung masih menyesuaikan diri dan mempelajari sistem kerja dalam perusahaan, serta mencari bantuan maupun dukungan dari rekan kerjanya. Dimana dukungan dari rekan di tempat kerja juga dapat meningkatkan kreativitas pada karyawan (Paramitha \& Indarti, 2014). yang menjadikan karyawan seperti ini cenderung menerapkan kreativitas dalam pekerjaannya. Hal ini yang pada akhirnya menjadikan karyawan dengan masa kerja yang lebih lama memiliki kreativitas yang lebih rendah.

\section{Kesimpulan}

Penelitian ini menemukan bahwa terdapat hubungan tidak langsung antara CSE dengan kreativitas karyawan melalui motivasi intrinsik. Namun demikian, budaya organisasi pembelajaran ditemukan tidak memoderasi hubungan antara motivasi intrinsik dan kreativitas karyawan. Terakhir, hasil penelitian menunjukkan budaya organisasi pembelajaran juga tidak memoderasi hubungan tidak langsung antara CSE dan kreativitas karyawan melalui motivasi intrinsik.

Penelitian ini memiliki beberapa keterbatasan, diantaranya adalah desain penelitian korelasional yang membatasi penelitian untuk menentukan efek kausalitas dari variabel-variabel penelitian yang digunakan. Penelitian selanjutnya disarankan untuk menggunakan metode lain yang dapat mengatasi kekurangan ini, misalnya studi longitudinal. Ada kemungkinan kreativitas karyawan mengalami fluktuasi dari waktu ke waktu, sehingga data longitudinal akan lebih kaya karena memperhitungkan variasi dari kreativitas dalam waktu yang berbeda. Kedua, penelitian ini dilakukan pada sebuah organisasi BUMD yang mungkin tidak dapat merefleksikan kreativitas yang diinginkan, 
dan juga tidak memiliki budaya organisasi pembelajaran. Penelitian selanjutnya dapat mereplikasi model penelitian serupa pada organisasi yang lebih dinamis dan kreatif, seperti start-up, NGO, dan perusahaan yang memiliki divisi research and development. Ketiga, penelitian ini menggunakan alat ukur berbentuk self-report dalam mengukur semua variabel, sehingga data yang diperoleh hanya berdasarkan persepsi responden saja. Hal ini terutama dapat memunculkan bias seperti social desirability issues dari responden karena karyawan hanya mengasumsikan tingkat kreativitasnya. Mengambil data secara self-report pada seluruh variabel penelitian juga meningkatkan potensi common method bias. Penelitian selanjutnya disarankan menggunakan alat ukur otherreport dari atasan atau dari rekan kerja untuk mengukur kreativitas karyawan. Penelitian selanjutnya disarankan juga untuk menggunakan variabel lingkungan lainnya yang dapat mempengaruhi kreativitas karyawan seperti peran pemimpin, maupun tim kerja. 
Apakah Budaya Organisasi Pembelajaran dapat Memoderasi Hubungan Tidak Langsung Antara Core-self Evaluation dan Kreativitas Karyawan Melalui Motivasi

Intrinsik

\section{BIBLIOGRAFI}

Amabile, T. M. (1983). The Social Psychology of Creativity. In The Social Psychology of Creativity. Springer New York. Google Scholar

Amabile, T. M. (1996). Creativity in context. In Westview Press. Westview: Boulder, Colo. Google Scholar

Anderson, N., Potočnik, K., \& Zhou, J. (2014). Innovation and Creativity in Organizations: A State-of-the-Science Review, Prospective Commentary, and Guiding Framework. Journal of Management, 40(5), 1297-1333. Google Scholar

Badan Pengawasan Keuangan dan Pembangunan. (2014). Reviu Literatur Pengelolaan Badan Usaha Milik Daerah.

Bank Aceh. (2018). Visi, Misi \& Motto.

Bank Aceh Syariah. (2019). Laporan Tahunan.

Chang, C. H., Ferris, D. L., Johnson, R. E., Rosen, C. C., \& Tan, J. A. (2012). Core selfevaluations: A review and evaluation of the literature. Journal of Management, 38(1), 81-128. Google Scholar

Cheung, M. F. Y., \& Wong, C. S. (2011). Transformational leadership, leader support, and employee creativity. Leadership \& Organization Development Journal, 32(7), 656-672. Google Scholar

Chiang, Y. H., Hsu, C. C., \& Hung, K. P. (2014). Core self-evaluation and workplace creativity. Journal of Business Research, 67(7), 1405-1413. Google Scholar

Choi, I. (2020). Moving beyond Mandates: Organizational Learning Culture, Empowerment, and Performance. International Journal of Public Administration, 43(8), 724-735. Google Scholar

Cozby, P. C., \& Bates, S. C. (2011). Methods in Behavioral Research (11th ed.). New York: McGraw-Hill. Google Scholar

Crick, N. R., \& Dodge, K. A. (1994). A Review and Reformulation of Social Information-Processing Mechanisms in Children's Social Adjustment. Psychological Bulletin, 115(1), 74-101.

Dewett, T. (2006). Exploring the role of risk in employee creativity. Journal of Creative Behavior, 40(1), 27-45. Google Scholar

Elliot, A. J. (1999). Approach and avoidance motivation and achievement goals. Educational Psychologist, 34(3), 169-189. Google Scholar

Elliot, A. J., \& McGregor, H. A. (2001). A $2 \times 2$ achievement goal framework. Journal 
of Personality and Social Psychology, 80(3), 501-519. Google Scholar

Elliot, A. J., \& Thrash, T. M. (2002). Approach-avoidance motivation in personality: Approach and avoidance temperaments and goals. Journal of Personality and Social Psychology, 82(5), 804-818. Google Scholar

Ferguson, M. J., \& Bargh, J. A. (2008). Evaluative readiness: The motivational nature of automatic evaluation. In Handbook of approach and avoidance motivation. (pp. 289-306). New York, NY, US: Psychology Press. Google Scholar

Ferris, D. L., Rosen, C. R., Johnson, R. E., Brown, D. J., Risavy, S. D., \& Heller, D. (2011). Approach or avoidance (Or both?): Integrating core self-evaluations within an approach/avoidance framework. Personnel Psychology, 64(1), 137-161. Google Scholar

Garvin, D. A. (1993). Building a learning organization. Harvard Business Review, 71(4), 78-91. Google Scholar

George, J. M., \& Zhou, J. (2001). When openness to experience and conscientiousness are related to creative behavior: An interactional approach. Journal of Applied Psychology, 86(3), 513-524. Google Scholar

Hahn, M. H., Lee, K. C., \& Lee, D. S. (2015). Network structure, organizational learning culture, and employee creativity in system integration companies: The mediating effects of exploitation and exploration. Computers in Human Behavior, 42, 167-175. Google Scholar

Hayes, A. F. (2018). Introduction to Mediation, Moderation, and Conditional Process Analysis (2nd ed.). New York: Guilford Press. Google Scholar

Hirst, G., Van Knippenberg, D., Chen, C.-H., \& Sacramento, C. A. (2011). How does bureaucracy impact individual creativity? A cross-level investigation of team contextual influences on goal orientation \& creativity relationship. The Academy of Management Journal, 54(3), 624-641. Google Scholar

Hoffmann, J., Ivcevic, Z., \& Brackett, M. (2016). Creativity in the Age of Technology: Measuring the Digital Creativity of Millennials. 28(2), 149-153. Google Scholar

Jeong, S., McLean, G. N., McLean, L. D., Yoo, S., \& Bartlett, K. (2017). The moderating role of non-controlling supervision and organizational learning culture on employee creativity: The influences of domain expertise and creative personality. European Journal of Training and Development, 41(7), 647-666. Google Scholar

Jones, B. F., \& Weinberg, B. A. (2011). Age dynamics in scientific creativity. Proceedings of the National Academy of Sciences of the United States of America, 108(47), 18910-18914. Google Scholar 
Joo, B. K. (Brian), \& Shim, J. H. (2010). Psychological empowerment and organizational commitment: The moderating effect of organizational learning culture. Human Resource Development International, 13(4), 425-441. Google Scholar

Judge, T. A., Erez, A., \& Bono, J. E. (1998). The power of being positive: The relation between positive self-concept and job performance. Human Performance, 11(2-3), 167-187. Google Scholar

Judge, T. A., Erez, A., Bono, J. E., \& Thoresen, C. J. (2003). The core self-evaluations scale: Development of a measure. Personnel Psychology, 56(2), 303-331. Google Scholar

Judge, T. A., \& Kammeyer-Mueller, J. D. (2011). Implications of core self-evaluations for a changing organizational context. Human Resource Management Review, 21(4), 331-341. Google Scholar

Kim, S. L. (2019). The interaction effects of proactive personality and empowering leadership and close monitoring behaviour on creativity. Creativity and Innovation Management, 28(2), 230-239. Google Scholar

Liu, D., Jiang, K., Shalley, C. E., Keem, S., \& Zhou, J. (2016). Motivational mechanisms of employee creativity: A meta-analytic examination and theoretical extension of the creativity literature. Organizational Behavior and Human Decision Processes, 137, 236-263. Google Scholar

Madjar, N., Greenberg, E., \& Chen, Z. (2011). Factors for Radical Creativity, Incremental Creativity, and Routine, Noncreative Performance. Journal of Applied Psychology, 96(4), 730-743. Google Scholar

Marsick, V. J., \& Watkins, K. E. (2003). Demonstrating the Value of an Organization's Learning Culture: The Dimensions of the Learning Organization Questionnaire. Advances in Developing Human Resources, 5(2), 132-151. Google Scholar

McLean, L. D. (2005). Organizational Culture's Influence on Creativity and Innovation: A Review of the Literature and Implications for Human Resource Development. Advances in Developing Human Resources, 7(2), 226-246. Google Scholar

Mehta, M., Chandani, A., \& Neeraja, B. (2014). Creativity and Innovation: Assurance for growth. Procedia Economics and Finance, 11, 804-811. Google Scholar

Memon, M. A., Cheah, J.-H., Ramayah, T., Ting, H., Chuah, F., \& Cham, T. H. (2019). Moderation Analysis: Issues And Guidelines. Journal of Applied Structural Equation Modeling, 3(1), 1-11. Google Scholar

Mumford, M. D., Scott, G. M., Gaddis, B., \& Strange, J. M. (2002). Leading creative people: Orchestrating expertise and relationships. Leadership Quarterly, 13(6), 705-750. Google Scholar 
Paramitha, A., \& Indarti, N. (2014). Impact of the Environment Support on Creativity: Assessing the Mediating Role of Intrinsic Motivation. Procedia - Social and Behavioral Sciences, 115, 102-114. Google Scholar

Podsakoff, P. M., MacKenzie, S. B., Lee, J. Y., \& Podsakoff, N. P. (2003). Common Method Biases in Behavioral Research: A Critical Review of the Literature and Recommended Remedies. Journal of Applied Psychology, 88(5), 879-903.

Reiter-Palmon, R., \& Illies, J. J. (2004). Leadership and creativity: Understanding leadership from a creative problem-solving perspective. Leadership Quarterly, 15(1), 55-77. Google Scholar

Shalley, C. E. (1995). Effects of coaction, expected evaluation, and goal setting on creativity and productivity. Academy of Management Journal, 38(2), 483-503. Google Scholar

Shalley, Christina E., \& Gilson, L. L. (2004). What leaders need to know: A review of social and contextual factors that can foster or hinder creativity. Leadership Quarterly, 15(1), 33-53. Google Scholar

Song, J. H., Chermack, T. J., \& Kim, W. (2013). An Analysis and Synthesis of DLOQBased Learning Organization Research. Advances in Developing Human Resources, 15(2), 222-239. Google Scholar

Tierney, P., Farmer, S. M., \& Graen, G. B. (1999). An examination of leadership and employee creativity: The relevance of traits and relationships. Personnel Psychology, 52(3), 591-620. Google Scholar

Tran, H. Q., \& Pham, N. T. B. (2019). Organizational learning as a moderator of the effect of employee participation on academic results: An empirical study in Vietnam. Learning Organization, 26(2), 146-159. Google Scholar

Wang, C. J., \& Wu, L. Y. (2012). Team member commitments and start-up competitiveness. Journal of Business Research, 65(5), 708-715. Google Scholar

Wang, Z., Bu, X., \& Cai, S. (2021). Core self-evaluation, individual intellectual capital and employee creativity. Current Psychology, 40(3), 1203-1217. Google Scholar

Woodman, R. W., Sawyer, J. E., \& Griffin, R. W. (1993). Toward a Theory of Organizational Creativity. The Academy of Management Review, 18(2), 293. https://doi.org/10.2307/258761 Google Scholar

Woodman, R. W., \& Schoenfeldt, L. F. (1990). An Interactionist Model of Creative Behavior. The Journal of Creative Behavior, 24(1), 10-20. Google Scholar

Zhang, X., \& Bartol, K. M. (2010). Linking empowering leadership and employee creativity: the influence of psychological empowerment, intrinsic motivation, and 
Apakah Budaya Organisasi Pembelajaran dapat Memoderasi Hubungan Tidak Langsung Antara Core-self Evaluation dan Kreativitas Karyawan Melalui Motivasi

Intrinsik

creative process engagement. Academy of Management Journal, 53(1), 107-128.

Zhang, Y., Sun, J. M. (James), Lin, C. H. (Veronica), \& Ren, H. (2020). Linking Core Self-Evaluation to Creativity: the Roles of Knowledge Sharing and Work Meaningfulness. Journal of Business and Psychology, 35(2), 257-270.

Zhou, J., \& George, J. M. (2001). When job dissatisfaction leads to creativity: Encouraging the expression of voice. Academy of Management Journal, 44(4), 682-696. Google Scholar

Zhou, J., \& Shalley, C. E. (2003). Research on Employee Creativity: a Critical Review and Directions for Future Research. Research in Personnel and Human Resources Management, 22, 165-217. Google Scholar

\section{Copyright holder:}

Affan Maulana Ghiffari, Debora Eflina Purba (2021)

First publication right:

Syntax Literate: Jurnal Ilmiah Indonesia

This article is licensed under:

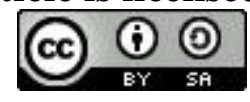

